\title{
Synthesis and Properties of Novel Aromatic Poly(ester amide)s Bearing Naphthalene-2,7-diyl Units
}

\author{
Sheng-Huei HsiaO, ${ }^{\dagger}$ Wen-Tsuen LEU, and Wenjeng GuO* \\ Department of Chemical Engineering, Tatung University, 40 Chungshan North Road, 3rd Section, \\ Taipei 104, Taiwan, Republic of China \\ *Department of Chemical Engineering, National Taipei Technology University, 1 Chunghsiao East Road, 3rd Section, \\ Taipei 100, Taiwan, Republic of China
}

(Received August 14, 2002; Accepted October 22, 2002)

\begin{abstract}
Two new naphthalene ring-containing diamino-diesters, 2,7-bis(4-aminobenzoyloxy)naphthalene $(p-2)$ and 2,7-bis(3-aminobenzoyloxy)naphthalene $(m-2)$, were synthesized from the condensation of 2,7dihydroxynaphthalene with 4-nitrobenzoyl chloride and 3-nitrobenzoyl chloride, respectively, followed by catalytic hydrogenation. Two series of naphthalene-containing poly(ester amide)s with inherent viscosities of 0.49-0.97 and 0.36$0.73 \mathrm{dL} \mathrm{g}^{-1}$ were prepared by the phosphorylation polyamidation of $p-\mathbf{2}$ and $m-\mathbf{2}$, respectively, with various aromatic dicarboxylic acids. Most of the poly(ester amide)s had excellent solubilities in polar aprotic solvents such as $N$-methyl2-pyrrolidone and $N, N$-dimethylacetamide, especially for the $m$-series polymers. Some of the poly(ester amide)s could be cast into transparent, flexible, and tough films from DMAc solutions. The poly(ester amide)s derived from rigid dicarboxylic acids such as terephthalic acid, 4,4'-biphenyldicarboxylic acid, 2,6-naphthalenedicarboxylic acid and 4,4'sulfonyldibenzoic acid were semicrystalline and showed less solubility. Except for three examples, most of the poly(ester amide)s displayed discernible glass transitions between 187 and $237^{\circ} \mathrm{C}$ in the DSC traces. These poly(ester amide)s showed insignificant decomposition below $400^{\circ} \mathrm{C}$ in nitrogen or air. The investigation of the thermal decomposition of the poly(ester amide)s using infrared spectroscopy and pyrolysis-gas chromatography/mass spectrometry (pyrolysisGC/MS) indicated that the primary breakage of the ester linkages started at around $400{ }^{\circ} \mathrm{C}$, which initiated the polymer chain scission.

KEY WORDS Naphthalene Units / Diamino-Diester / Poly(ester amide)s / Pyrolysis-Gas Chromatography/Mass Spectrometry (Pyrolysis-GC/MS) /
\end{abstract}

Wholly aromatic polyamides (aramids) belong to the class of high-performance materials with useful properties such as high thermal stability, chemical resistance, low flammability and excellent mechanical properties. ${ }^{1-3}$ For example, commercially known Kevlar (poly- $p$-phenyleneterephthalamide) and Nomex (poly$m$-phenyleneisophthalamide) are composed of phenylene units linked via an amide group and exhibit high crystallinity. Thus, they are useful as ultrahighstrength and high-modulus fibers. However, these aramids are usually difficult to process into articles due to their high glass-transition or melting temperatures and limited solubility in common organic solvents caused by the high crystallinity and high stiffness of the polymer backbones. Processable engineering plastics possessing moderately high softening temperatures and/or solubility in some organic solvents are required for practical use. Several successful approaches of the chemical structure modification to increase the processability of these aramids are the introduction of flexible links, ${ }^{4-6}$ asymmetric units, ${ }^{7-9}$ bulky pendant groups ${ }^{10-13}$ or crank and twisted non- coplanar structures ${ }^{14-17}$ into backbones of the aramids. It has been demonstrated that incorporation both ether and naphthyl units into the polymer backbones is a successful route to improve the solubility of aramids while retaining high thermal stability. ${ }^{18-22}$ In connection with our interest in preparing easily processable high-performance polymers bearing naphthyl units, this study deals with the synthesis and basic characterization of novel aromatic poly(ester amide)s derived from the diamino-diesters bearing naphthalene-2,7-diyl unit, i.e., 2,7-bis(4-aminobenzoyloxy)naphthalene ( $p$ 2) and 2,7-bis(3-aminobenzoyloxy)naphthalene ( $m-2)$, with various aromatic dicarboxylic acids. The solubility behavior and thermal properties of the poly(ester amide)s obtained from diamine $p-\mathbf{2}$ are compared with those of structurally related poly(ether amide)s from 2,7-bis(4-aminophenoxy)naphthalene. ${ }^{18}$ Because the understanding of the thermal decomposition behavior of a polymer is of crucial importance in its end use application, the thermal decomposition of the resultant poly(ester amide)s was also investigated by using pyrolysis-GC/MS analysis.

${ }^{\dagger}$ To whom correspondence should be addressed (E-mail: shhsiao@ttu.edu.tw). 


\section{EXPERIMENTAL}

\section{Materials}

2,7-Dihydroxynaphthalene (from Acros), 4nitrobenzoyl chloride (from Acros), 3-nitrobenzoyl chloride (from Acros), and 10\% palladium on activated carbon $(\mathrm{Pd} / \mathrm{C}$, from Fluka) were used as received. Terephthalic acid (3a, from Fluka), isophthalic acid (3b, from Wako), 5-tert-butylisophthalic acid (3c, from Aldrich), 4,4'-biphenyldicarboxylic acid (3d, from TCI), 2,6-naphthalenedicarboxylic acid (3e, from TCI), 4,4'-oxydibenzoic acid (3f, from TCI), 4,4'-hexafluoroisopropylidenedibenzoic acid (3g, from Chriskev), and 4,4'-sulfonyldibenzoic acid (3h , from New Japan Chemical Co.) were used as received. 4,4'[Isopropylidenebis(1,4-phenylene)dioxy]dibenzoic acid (3i, $\left.\mathrm{mp} 276^{\circ} \mathrm{C}\right)$ and 4,4'-[hexafluoroisopropylidenebis(1,4-phenylene)dioxy]dibenzoic acid (3j, mp $318^{\circ} \mathrm{C}$ ) were synthesized in high purity and high yields via two steps from commercially available reagents. ${ }^{5}$ Commercially available reagent-grade anhydrous calcium chloride $\left(\mathrm{CaCl}_{2}\right)$ and lithium chloride $(\mathrm{LiCl})$ were dried under vacuum at $180^{\circ} \mathrm{C}$ for $8 \mathrm{~h}$ prior to use. $N$-Methyl-2-pyrrolidone (NMP), $N, N$ dimethylformamide (DMF), N,N-dimethylacetamide (DMAc), and pyridine were purified by distillation under reduced pressure over calcium hydride and stored over $4 \AA$ molecular sieves. Triphenyl phosphite (TPP) was also purified by distillation under reduced pressure.

\section{Monomer Synthesis}

2,7-Bis(4-nitrobenzoyloxy)naphthalene ( $p-1)$ and 2,7-Bis(3-nitrobenzoyloxy)naphthalene (m-1). 2,7Dihydroxynaphthalene $(16 \mathrm{~g} ; 0.1 \mathrm{~mol})$, which was dissolved in $400 \mathrm{~mL}$ of dried DMAc, and triethylamine $(30 \mathrm{~mL} ; 0.22 \mathrm{~mol})$ were mixed in a $1 \mathrm{~L}$ round-bottomed flask. A solution of 4-nitrobenzoyl chloride (39 g; $0.21 \mathrm{~mol})$ in DMAc $(100 \mathrm{~mL})$ was then added dropwise over a period of about $1 \mathrm{~h}$. After complete addition, the reaction mixture was stirred at $80^{\circ} \mathrm{C}$ for $8 \mathrm{~h}$. The reaction mixture was then poured into $1.5 \mathrm{~L}$ of water. The precipitate was collected by filtration, washed thoroughly with water and methanol, and dried. The crude product $(43.9 \mathrm{~g} ; 96 \%$ yield) was purified by recrystallization from DMF to give $40.7 \mathrm{~g}$ (89\% yield) of pure $p$-1 as light yellowish crystals; mp $238^{\circ} \mathrm{C}$ (DSC, $10^{\circ} \mathrm{C} \mathrm{min}^{-1}$ ).

IR (KBr): $1734(\mathrm{C}=\mathrm{O}), 1531,1350\left(-\mathrm{NO}_{2}\right), 1269$, $1140 \mathrm{~cm}^{-1}(\mathrm{C}-\mathrm{O})$.

${ }^{1} \mathrm{H}$ NMR (400 MHz, DMSO- $\left.d_{6}\right), \delta(\mathrm{ppm}): 8.44(\mathrm{~s}$, $\left.\mathrm{H}_{\mathrm{d}}+\mathrm{H}_{\mathrm{e}}, 8 \mathrm{H}\right), 8.15\left(\mathrm{~d}, J=8.8 \mathrm{~Hz}, \mathrm{H}_{\mathrm{c}}, 2 \mathrm{H}\right), 7.95\left(\mathrm{~s}, \mathrm{H}_{\mathrm{a}}\right.$,
$2 \mathrm{H}), 7.59\left(\mathrm{~d}, J=8.8 \mathrm{~Hz}, \mathrm{H}_{\mathrm{b}}, 2 \mathrm{H}\right)$.

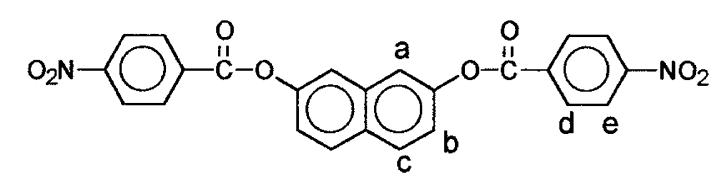

Anal. Calcd for $\mathrm{C}_{24} \mathrm{H}_{14} \mathrm{~N}_{2} \mathrm{O}_{8}$ (458.38): C, 62.89\%; $\mathrm{H}, 3.08 \%$; N, 6.11\%. Found: C, 62.96\%; H, 3.09\%; N, $6.13 \%$.

Dinitro compound $m-\mathbf{1}$ was synthesized from 2,7dihydroxynaphthalene and 3-nitrobenzoyl chloride according to the same procedure. Pure $m-\mathbf{1}$ ( $86 \%$ yield) was obtained as off-white crystals by recrystallization from glacial acetic acid; $\mathrm{mp} 167^{\circ} \mathrm{C}$ (DSC, $10^{\circ} \mathrm{C}$ $\left.\min ^{-1}\right)$.

IR $(\mathrm{KBr}): 1739(\mathrm{C}=\mathrm{O}), 1529,1350\left(-\mathrm{NO}_{2}\right), 1284$, $1144 \mathrm{~cm}^{-1}(\mathrm{C}-\mathrm{O})$.

${ }^{1} \mathrm{H}$ NMR (400 MHz, DMSO- $\left.d_{6}\right), \delta(\mathrm{ppm}): 8.81$ (s, $\left.\mathrm{H}_{\mathrm{g}}, 2 \mathrm{H}\right), 8.56\left(\mathrm{~d}, J=8.0 \mathrm{~Hz}, \mathrm{H}_{\mathrm{d}}, 2 \mathrm{H}\right), 8.56(\mathrm{~d}, J=$ $\left.8.0 \mathrm{~Hz}, \mathrm{H}_{\mathrm{f}}, 2 \mathrm{H}\right), 8.11\left(\mathrm{~d}, J=8.9 \mathrm{~Hz}, \mathrm{H}_{\mathrm{c}}, 2 \mathrm{H}\right), 7.91$ $\left(\mathrm{t}, J=8.0 \mathrm{~Hz}, \mathrm{H}_{\mathrm{e}}, 2 \mathrm{H}\right), 7.91\left(\mathrm{~s}, \mathrm{H}_{\mathrm{a}}, 2 \mathrm{H}\right), 7.56(\mathrm{~d}, J=$ $\left.8.9 \mathrm{~Hz}, \mathrm{H}_{\mathrm{b}}, 2 \mathrm{H}\right)$.

${ }^{13} \mathrm{C}$ NMR (100 MHz, DMSO- $\left.d_{6}\right): \quad \delta(\mathrm{ppm}) 162.9$ $(\mathrm{C}=\mathrm{O}), 148.8\left(\mathrm{C}^{3}\right), 147.9\left(\mathrm{C}^{11}\right), 135.8\left(\mathrm{C}^{8}\right), 133.7\left(\mathrm{C}^{1}\right)$, $130.8\left(\mathrm{C}^{9}\right), 130.5\left(\mathrm{C}^{7}\right), 129.5\left(\mathrm{C}^{10}\right), 129.4\left(\mathrm{C}^{6}\right), 128.3$ $\left(C^{5}\right), 124.1\left(C^{12}\right), 121.4\left(C^{2}\right), 118.5\left(C^{4}\right)$.

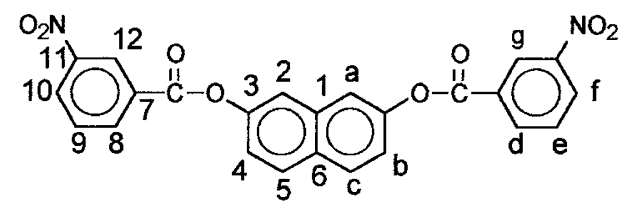

Anal. Calcd for $\mathrm{C}_{24} \mathrm{H}_{14} \mathrm{~N}_{2} \mathrm{O}_{8}$ (458.38): C, 62.89\%; H, 3.08\%; N, 6.11\%. Found: C, 62.83\%; H, 3.14\%; N, $6.13 \%$.

2,7-Bis(4-aminobenzoyloxy)naphthalene ( $p$-2) and 2,7-Bis(3-aminobenzoyloxy)naphthalene ( $m-2)$. Diamino-diesters $p$-2 and $m$-2 were synthesized by the catalytic hydrogenation of dinitro compounds $p-\mathbf{1}$ and $m-1$, respectively. A mixture of $32.4 \mathrm{~g}(0.071 \mathrm{~mol})$ of $p$-1 and $0.4 \mathrm{~g}$ of $10 \% \mathrm{Pd} / \mathrm{C}$ in $600 \mathrm{~mL}$ of DMAc was stirred at room temperature under a hydrogen atmosphere until the theoretical amount of hydrogen was consumed. The time taken to reach this stage was about $3 \mathrm{~d}$. The solution was filtered to remove the catalyst, and the obtained filtrate was poured into $2 \mathrm{~L}$ of stirring water to give a white precipitate. The yield was $24.6 \mathrm{~g}(87 \%) ; \mathrm{mp} 273{ }^{\circ} \mathrm{C}\left(\mathrm{DSC}, 10^{\circ} \mathrm{C} \mathrm{min}{ }^{-1}\right)$.

IR (KBr): 3471, $3375\left(\mathrm{NH}_{2}\right), 1701(\mathrm{C}=\mathrm{O}), 1273$, $1144 \mathrm{~cm}^{-1}(\mathrm{C}-\mathrm{O})$.

${ }^{1} \mathrm{H}$ NMR (400 MHz, DMSO- $d_{6}$ ), $\delta(\mathrm{ppm}): 8.03(\mathrm{~d}$, $J=8.8 \mathrm{~Hz}, 2 \mathrm{H}), 7.90(\mathrm{~d}, J=8.6 \mathrm{~Hz}, 4 \mathrm{H}), 7.78(\mathrm{~s}, 2 \mathrm{H})$, $7.40(\mathrm{~d}, J=8.8 \mathrm{~Hz}, 2 \mathrm{H}), 6.71(\mathrm{~d}, J=8.6 \mathrm{~Hz}, 4 \mathrm{H}), 6.21$ (s, $\left.\mathrm{NH}_{2}, 4 \mathrm{H}\right)$. 
${ }^{13} \mathrm{C}$ NMR (100 MHz, DMSO- $\left.d_{6}\right), \delta(\mathrm{ppm}): 164.7$, 154.3, 149.3, 134.0, 131.9, 129.0, 128.6, 121.6, 118.4, 114.4, 112.8.

Anal. Calcd for $\mathrm{C}_{24} \mathrm{H}_{18} \mathrm{~N}_{2} \mathrm{O}_{4}$ (398.42): C, $72.35 \%$; $\mathrm{H}, 4.55 \%$; N, $7.03 \%$. Found: C, 72.31\%; H, 4.88\%; N, $7.14 \%$.

Diamino-diester $m-2$ was synthesized from dinitro compound $m-\mathbf{1}$ as a light grey crystalline product with

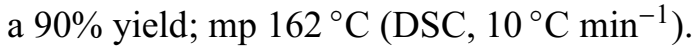

IR (KBr): 3433, $3354\left(\mathrm{NH}_{2}\right), 1711(\mathrm{C}=\mathrm{O}), 1302$, $1139 \mathrm{~cm}^{-1}(\mathrm{C}-\mathrm{O})$.

${ }^{1} \mathrm{H}$ NMR (400 MHz, DMSO- $\left.d_{6}\right), \delta(\mathrm{ppm}): 8.09(\mathrm{~d}$, $J=8.9 \mathrm{~Hz}, 2 \mathrm{H}), 7.86(\mathrm{~s}, 2 \mathrm{H}), 7.47(\mathrm{~d}, J=8.6 \mathrm{~Hz}$, $2 \mathrm{H}), 7.46(\mathrm{~s}, 2 \mathrm{H}), 7.35(\mathrm{~d}, J=7.6 \mathrm{~Hz}, 2 \mathrm{H}), 7.26(\mathrm{t}$, $J=7.8 \mathrm{~Hz}, 2 \mathrm{H}), 6.95(\mathrm{~d}, J=7.8 \mathrm{~Hz}, 2 \mathrm{H}), 5.52\left(\mathrm{~s}, \mathrm{NH}_{2}\right.$, $4 \mathrm{H})$.

${ }^{13} \mathrm{C}$ NMR $\left(100 \mathrm{MHz}\right.$, DMSO- $\left.d_{6}\right), \delta(\mathrm{ppm}): 165.3$, $149.2,149.1,133.9,129.6,129.3,129.0,121.5,119.1$, $118.8,118.5,117.0,114.6$.

Anal. Calcd for $\mathrm{C}_{24} \mathrm{H}_{18} \mathrm{~N}_{2} \mathrm{O}_{4}$ (398.42): C, $72.35 \%$; $\mathrm{H}, 4.55 \%$; N, 7.03\%. Found: C, 72.33\%; H, 4.65\%; N, $7.04 \%$.

\section{Polymer Synthesis}

A typical example of polycondensation is as follows. A mixture of $0.5976 \mathrm{~g}(1.5 \mathrm{mmol})$ of diamino-diester $p$ 2, $0.3334 \mathrm{~g}(1.5 \mathrm{mmol})$ of 5-tert-butylisophthalic acid (3c), $0.2 \mathrm{~g}$ of calcium chloride, $2.0 \mathrm{~mL}$ of NMP, $0.5 \mathrm{~mL}$ of pyridine, and $1.5 \mathrm{~mL}$ of TPP was heated with stirring at $110^{\circ} \mathrm{C}$ for $3 \mathrm{~h}$. As polycondensation proceeded, the solution became viscous gradually. The resulting highly viscous polymer solution was poured slowly into $250 \mathrm{~mL}$ of stirred methanol. The stringy, fiber-like precipitate was collected by filtration, washed thoroughly with methanol and hot water, and dried at $100^{\circ} \mathrm{C}$ in a vacuum oven. The yield was quantitative. The inherent viscosity of polymer $p-4 \mathrm{c}$ was $0.58 \mathrm{dL} \mathrm{g}^{-1}$, measured at a concentration of $0.5 \mathrm{~g} \mathrm{dL}^{-1}$ in DMAc containing 5 $\mathrm{wt} \% \mathrm{LiCl}$ at $30^{\circ} \mathrm{C}$. The FT-IR spectra (film) exhibited absorptions at 3319 (N-H stretching), 1736 (ester $\mathrm{C}=\mathrm{O}$ stretching), 1680 (amide $\mathrm{C}=\mathrm{O}$ stretching), $1533(\mathrm{~N}-$ $\mathrm{H}$ bending), 1259, $1142 \mathrm{~cm}^{-1}$ (C-O stretching). Other poly(ester amide)s were synthesized by an analogous procedure.

\section{Film Preparation}

A polymer solution was made by dissolving about $0.9 \mathrm{~g}$ of the polymer in $9 \mathrm{~mL}$ of hot DMAc to afford an approximate $10 \mathrm{wt} \%$ solution. The clear solution was poured into a $9-\mathrm{cm}$ diameter glass culture dish and then placed in a $80^{\circ} \mathrm{C}$ oven overnight to remove the solvent. The semidried polyamide film was stripped off from the glass surface and further dried in vacuo at $150^{\circ} \mathrm{C}$ for
$6 \mathrm{~h}$. The obtained films had about $0.1 \mathrm{~mm}$ in thickness and were used for solubility, thermal analysis, X-Ray diffraction, and tensile tests.

\section{Measurements}

IR spectra were recorded on a Horiba FT-720 Fourier transform infrared (FT-IR) spectrometer. ${ }^{1} \mathrm{H}$ and ${ }^{13} \mathrm{C}$ NMR spectra were recorded on a JEOL EX-400 NMR spectrometer with perdeuterodimethyl sulfoxide (DMSO- $d_{6}$ ) as the solvent and tetramethylsilane as the reference, working at 400 and $100 \mathrm{MHz}$, respectively. Elemental analyses were run in a PerkinElmer Model $2400 \mathrm{C}, \mathrm{H}, \mathrm{N}$ analyzer. The inherent viscosities of the polymers were determined at a concentration of $0.5 \mathrm{~g} \mathrm{dL}^{-1}$ in DMAc containing $5 \mathrm{wt} \%$ $\mathrm{LiCl}$ with a Cannon-Fenske viscometer at $30^{\circ} \mathrm{C}$. Differential scanning calorimetry (DSC) was performed on a PerkinElmer Pyris $1 \mathrm{DSC}$ at a heating rate of $20{ }^{\circ} \mathrm{C} \mathrm{min}^{-1}$ in flowing nitrogen $\left(20 \mathrm{~mL} \mathrm{~min}^{-1}\right)$. Thermogravimetric analysis (TGA) was conducted with a PerkinElmer Pyris 1 TGA. The experiments were carried out on $3-5 \mathrm{mg}$ samples heated at a heating rate of $20^{\circ} \mathrm{C} \mathrm{min}^{-1}$ in flowing nitrogen or air $(30 \mathrm{~mL}$ $\mathrm{min}^{-1}$ ). Thermomechanical analysis (TMA) was conducted with a PerkinElmer TMA 7 with a penetration probe $1.0 \mathrm{~mm}$ in diameter under an applied constant load of $10 \mathrm{mN}$. The TMA experiments were conducted in duplicate from 50 to $300^{\circ} \mathrm{C}$ at a scanning rate of $10^{\circ} \mathrm{C} \mathrm{min}{ }^{-1}$. Softening temperatures $\left(T_{\mathrm{s}}\right)$ were taken as the onset temperatures of probe displacement on the second TMA traces. Wide-angle X-Ray diffractograms were obtained on a Siemens Kristalloflex D5000 XRay diffractometer with nickel-filtered $\mathrm{Cu}-K \alpha$ radiation $(40 \mathrm{kV}, 15 \mathrm{~mA})$ by a scanning rate of $2^{\circ} \mathrm{min}^{-1}$ over a range of $2 \theta=5-45^{\circ}$, and measurements were performed at room temperature with film specimens about $0.1 \mathrm{~mm}$ thickness. An Instron universal tester model 1130 with a load cell of $5 \mathrm{~kg}$ was used to study the stress-strain behavior of the samples. A gauge length of $2 \mathrm{~cm}$ and a crosshead speed of $5 \mathrm{~mm} \mathrm{~min}^{-1}$ were used for this study. Measurements were performed at room temperature with film specimens $(0.5 \mathrm{~cm}$ wide, $6 \mathrm{~cm}$ long, and about $0.1 \mathrm{~mm}$ thick), and an average of at least five individual determinations was used. Pyrolysis-GC/MS analysis was run in a Frontier Laboratories model PY-2020iD Double-Shot Pyrolyzer coupled to an HP6890 series Gas Chromatograph linking to an HP5973 Mass Selective Detector.

\section{RESULTS AND DISCUSSION}

\section{Monomer Synthesis}

The new diamino-diesters $p-\mathbf{2}$ and $m$-2 were 

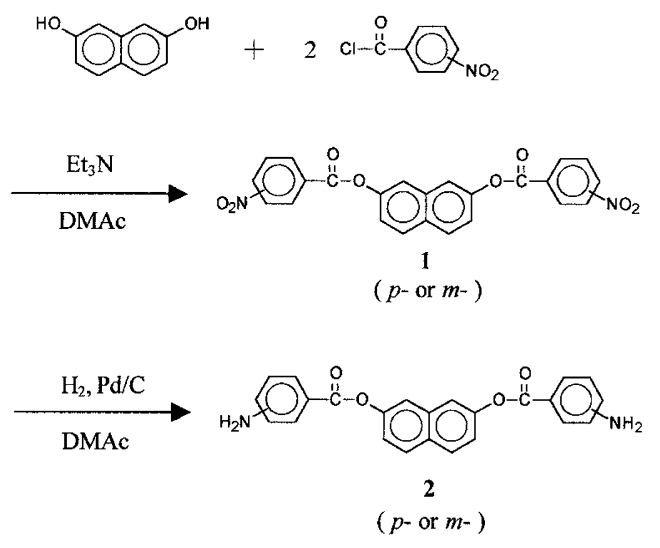

Scheme 1.

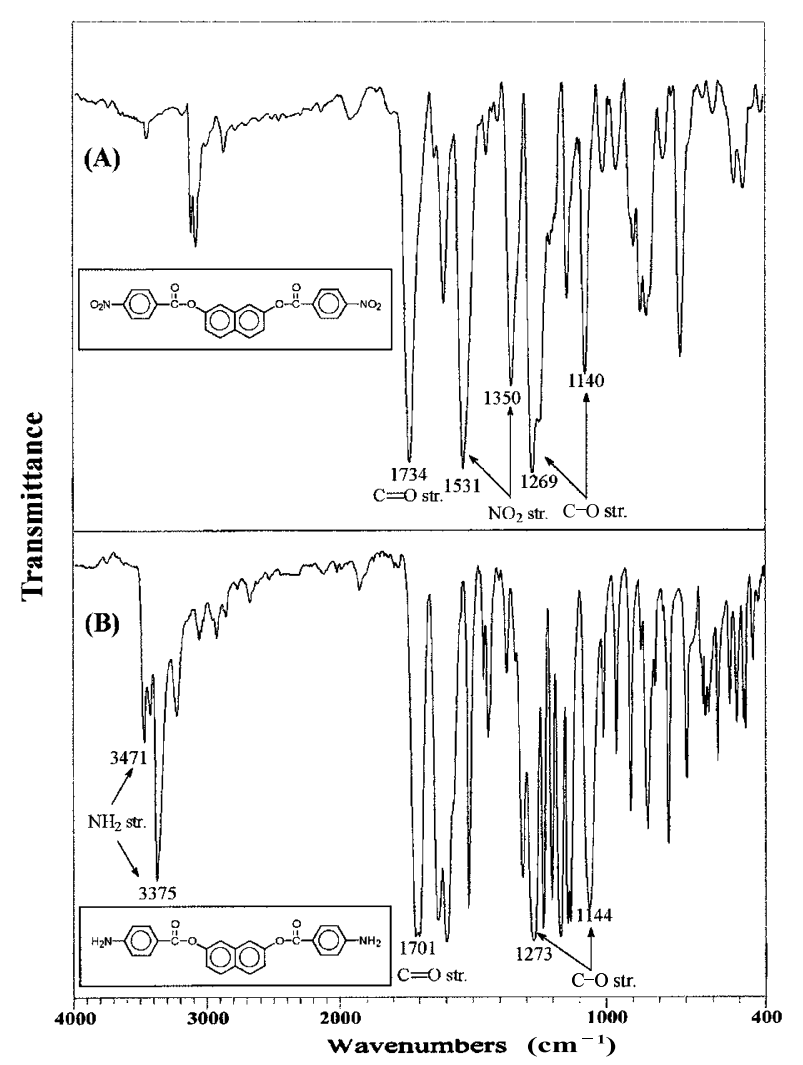

Figure 1. IR spectra of (A) dinitro compound $p$-1 and (B) diamine $p$-2.

successfully synthesized by using hydrogen $\mathrm{Pd} / \mathrm{C}$ catalyzed reduction of dinitro compounds $p-\mathbf{1}$ and $m-\mathbf{1}$ resulting from the condensation reaction of 2,7-dihydroxynaphthalene with 4-nitrobenzoyl chloride and 3-nitrobenzoyl chloride, as shown in Scheme 1. Elemental, IR, and NMR analyses were used to confirm the structures of all intermediates and monomers. The IR spectra of dinitro compound $p-\mathbf{1}$ and diamino-diester $p$-2 are illustrated in Figure 1. The nitro groups of $p-\mathbf{1}$ showed two characteristic absorption bands at 1531 and $1350 \mathrm{~cm}^{-1}$. After the reduction, the characteristic absorptions of the nitro groups disappeared, and the amino group showed a pair of $\mathrm{N}-\mathrm{H}$ stretching absorp-

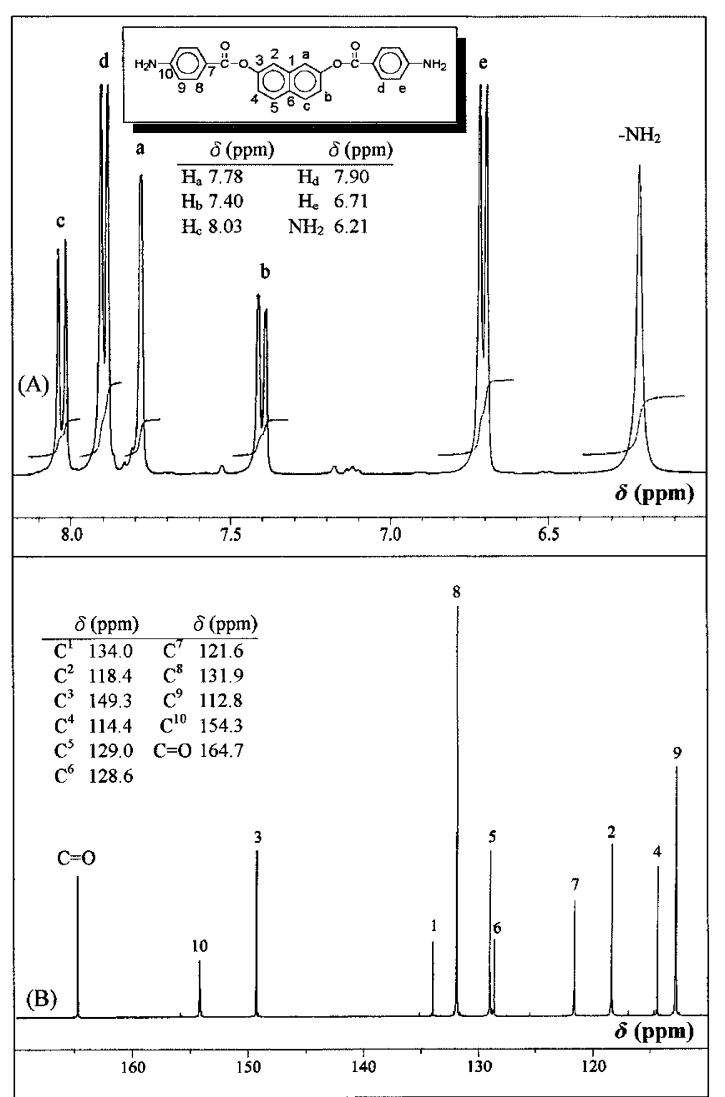

Figure 2. ${ }^{1} \mathrm{HNMR}(\mathrm{A})$ and ${ }^{13} \mathrm{C}$ NMR (B) spectra of $p$-2 in DMSO- $d_{6}$.

tion bands at 3471 and $3375 \mathrm{~cm}^{-1}$. In the IR spectrum of diamino-diester $p$-2, the characteristic absorption band at $1701 \mathrm{~cm}^{-1}$ was as signed to the ester carbonyl group, which is about $30 \mathrm{~cm}^{-1}$ lower than that of $p-1\left(1734 \mathrm{~cm}^{-1}\right)$. Conjugation of the amino group substituted at the para-position caused the absorption shift. The ${ }^{1} \mathrm{H}$ NMR and ${ }^{13} \mathrm{C}$ NMR spectra of the diamino-diesters are shown in Figures 2 and 3, respectively. Assignments of each carbon and proton also are given in the figures, and all the NMR spectroscopic data are consistent with the proposed structures. In the ${ }^{1} \mathrm{H}$ NMR spectra, a downfield chemical shift $\left(\delta_{\mathrm{H}}\right.$ is increased) usually corresponds to the decrease in the electron-donating property of the amino group. The electron-withdrawing effect is stronger for the parasubstituted ester carbonyl group than that substituted at the meta-position. Thus, the nucleophilicity for the amino groups of diamino-diester $m-2\left(\delta_{\mathrm{H}}=5.52 \mathrm{ppm}\right)$ was expected to be stronger than those of its paraisomer $\left(p-2 ; \delta_{\mathrm{H}}=6.21 \mathrm{ppm}\right)$. It also can be seen from the ${ }^{13} \mathrm{C}$ NMR spectra that the amino group attached carbon atoms $\left(\mathrm{C}^{10}\right)$ in $p$-2 resonated at a lower field $(\delta=$ $154.3 \mathrm{ppm})$ compared to the corresponding ones $\left(\mathrm{C}^{11}\right)$ in $m-2(\delta=149.2 \mathrm{ppm})$ because of the stronger electronwithdrawing effect of the carbonyl group in the former. 


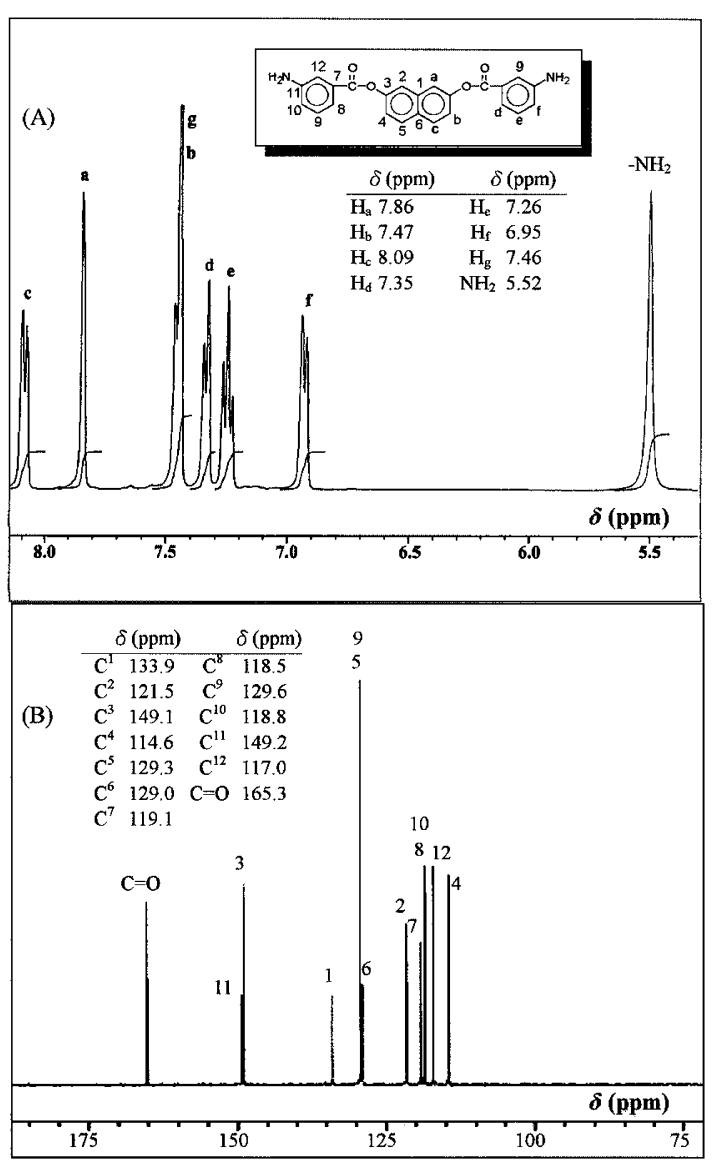

Figure 3. ${ }^{1} \mathrm{H} N M R(A)$ and ${ }^{13} \mathrm{C}$ NMR (B) spectra of $m-2$ in DMSO- $d_{6}$.

\section{Polymer Synthesis}

The direct polycondensation of aromatic diamines with aromatic dicarboxylic acids using triphenyl phosphite (TPP) and pyridine as condensing agents has been known to be a convenient method for the preparation of aromatic polyamides on laboratory scale. ${ }^{23}$ This method was adopted here to prepare two series of aromatic poly(ester amide)s $p-\mathbf{4 a - j}$ and $m-\mathbf{4 a - j}$ from diamino-diesters $p-\mathbf{2}$ and $m-\mathbf{2}$ with various aromatic dicarboxylic acids (3a-j) (Scheme 2). Synthesis conditions and inherent viscosities of poly(ester amide)s $p$ 4a-j and $m-\mathbf{4 a - j}$ are summarized in Table I. All the reaction solutions were homogeneously transparent and became highly viscous, except for polymers $p-\mathbf{4 a}$ and $p-\mathbf{4 d - f}$, which precipitated from the reaction medium when the reaction systems became viscous. These two series of poly(ester amide)s were obtained in almost quantitative yields with inherent viscosities of 0.49 $0.97 \mathrm{dL} \mathrm{g}^{-1}$ for $p-\mathbf{4 a - j}$ and $0.36-0.73 \mathrm{dL} \mathrm{g}^{-1}$ for $m-\mathbf{4 a - j}$. The lower inherent viscosities of the $m$-series poly(ester amide)s, compared with those of the $p$-series, may be due in part to their more flexible structure. In interpreting the viscosity behavior, one must bear in mind that the inherent viscosities of a flexible polymer is much lower than that of a rigid polymer of a simi-

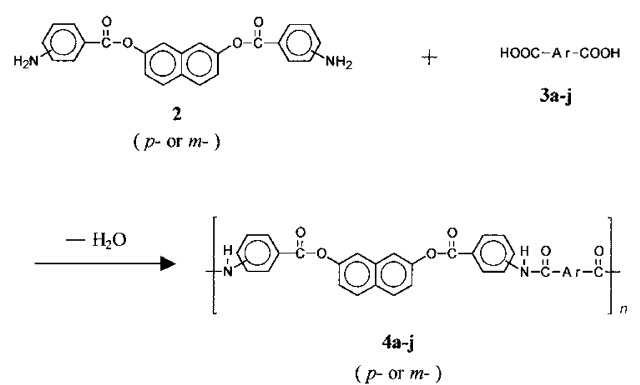

Ar :

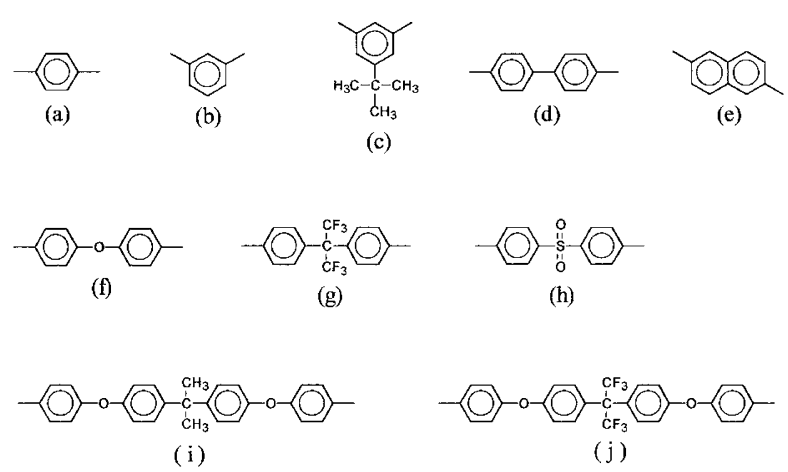

Scheme 2.

lar molecular weight. Except for $p-\mathbf{4 a}$ and $p-\mathbf{4 d - f}$, all the other poly(ester amide)s could be solution-cast into free-standing films. However, some films such as those of $p-\mathbf{4 h}, m-\mathbf{4 a}, m-\mathbf{4 b}, m-\mathbf{4 d}, m-\mathbf{4 e}$, and $m-\mathbf{4 h}$ cracked upon creasing, possibly because of a high level of crystallinity or structural rigidity. The other films were flexible and creasable, indicative of high molecular weight polymers. Structural features of the poly(ester amide)s were verified by IR spectroscopy. They showed the characteristic absorptions of the amide group around $3320 \mathrm{~cm}^{-1}$ (N-H stretching), $1670-1680 \mathrm{~cm}^{-1}$ (amide $\mathrm{C}=\mathrm{O}$ stretching) and $1530-1550 \mathrm{~cm}^{-1}(\mathrm{~N}-$ $\mathrm{H}$ bending). All the polymers also exhibited IR bands at $1730-1740 \mathrm{~cm}^{-1}$ (ester $\mathrm{C}=\mathrm{O}$ stretching) and $1250-1270 \mathrm{~cm}^{-1}$ (C-O stretching) due to the ester groups.

\section{Properties of the Polymers}

All the poly(ester amide)s were structurally characterized by wide-angle X-Ray diffraction (WAXD) studies. As can be seen from the diffraction patterns shown in Figure 4, the poly(ester amide)s ( $p$ - or $m-\mathbf{4 a}, \mathbf{4 d}$, and 4e) derived from rigid diacids such as terephthalic acid (3a), 4,4'-biphenyldicarboxylic acid (3d), and 2,6-naphthalenedicarboxylic acid (3e) showed some diffraction signals of medium intensity assignable to a semicrystalline polymer. Polymer $p-\mathbf{4 h}$ and $m-\mathbf{4 h}$ also can be judged as semicrystalline on the basis of their WAXD patterns. This result seems to be correlative with the presence of polar sulfonyl groups that causes 
Table I. Synthesis conditions, inherent viscosities, and film quality of poly(ester amide)s

\begin{tabular}{|c|c|c|c|c|c|}
\hline \multirow[b]{2}{*}{ Polymer code } & \multicolumn{3}{|c|}{ Amount of reagent used ${ }^{a}$} & \multirow[b]{2}{*}{$\begin{array}{c}\eta_{\text {inh }^{\mathrm{c}}} \\
\left(\mathrm{dL} \mathrm{g}^{-1}\right)\end{array}$} & \multirow[b]{2}{*}{ Film quality ${ }^{\mathrm{d}}$} \\
\hline & $\begin{array}{l}\text { NMP } \\
(\mathrm{mL})\end{array}$ & $\begin{array}{l}\text { Pyridine } \\
\text { (mL) }\end{array}$ & $\begin{array}{c}\mathrm{CaCl}_{2} \\
(\mathrm{~g})\end{array}$ & & \\
\hline$p-\mathbf{4 a}$ & $5+5^{b}$ & 1.2 & 0.5 & 0.74 & $-^{\mathrm{e}}$ \\
\hline$p-4 b$ & 2 & 0.5 & 0.2 & 0.57 & $\mathrm{~F}$ \\
\hline$p-4 c$ & 2 & 0.5 & 0.2 & 0.58 & $\mathrm{~F}$ \\
\hline$p-4 d$ & $5+5$ & 1.2 & 0.5 & 0.95 & - \\
\hline$p-4 \mathrm{e}$ & 5 & 1.2 & 0.5 & 0.97 & - \\
\hline$p-\mathbf{4 f}$ & $4+2$ & 1.0 & 0.4 & 0.81 & - \\
\hline$p-4 g$ & 3 & 0.8 & 0.3 & 0.56 & $\mathrm{~F}$ \\
\hline$p-4 h$ & $3+1$ & 0.8 & 0.3 & 0.49 & B \\
\hline$p-4 \mathbf{i}$ & 3 & 0.8 & 0.3 & 0.68 & $\mathrm{~F}$ \\
\hline$p-4 \mathbf{j}$ & 3 & 0.8 & 0.3 & 0.59 & $\mathrm{~F}$ \\
\hline$m-\mathbf{4 a}$ & 4 & 1.0 & 0.4 & 0.45 & B \\
\hline$m-4 b$ & 2 & 0.5 & 0.2 & 0.36 & B \\
\hline$m-4 c$ & 2 & 0.5 & 0.2 & 0.51 & $\mathrm{~F}$ \\
\hline$m-\mathbf{4 d}$ & 4 & 1.0 & 0.4 & 0.73 & B \\
\hline$m-4 \mathrm{e}$ & 4 & 1.0 & 0.4 & 0.70 & B \\
\hline$m-\mathbf{4 f}$ & 3 & 0.8 & 0.3 & 0.53 & $\mathrm{~F}$ \\
\hline$m-\mathbf{4 g}$ & $2+1$ & 0.5 & 0.2 & 0.50 & $\mathrm{~F}$ \\
\hline$m-4 h$ & 3 & 0.8 & 0.3 & 0.50 & B \\
\hline$m-4 \mathbf{i}$ & 3 & 0.8 & 0.3 & 0.57 & $\mathrm{~F}$ \\
\hline$m-\mathbf{4} \mathbf{j}$ & 2 & 0.5 & 0.2 & 0.52 & $\mathrm{~F}$ \\
\hline
\end{tabular}

${ }^{a}$ Amount of each diamino-diester and diacid monomer $=1.5 \mathrm{mmol}$; TPP $=1.5 \mathrm{~mL}$; reaction temperature $=110^{\circ} \mathrm{C}$; reaction time $=3 \mathrm{~h}$. ${ }^{\mathrm{b}}$ " $5+5$ " means that an initial amount of $5 \mathrm{~mL} \mathrm{NMP}$ was used and an additional $5 \mathrm{~mL}$ of NMP was added when the reaction solution became too viscous or turbid. ${ }^{\mathrm{c}}$ Measured at a concentration of $0.5 \mathrm{~g} \mathrm{dL}^{-1}$ in DMAc containing $5 \mathrm{wt} \% \mathrm{LiCl}$ at $30^{\circ} \mathrm{C}$ by a ConnonFenske viscometer. ${ }^{\mathrm{d}}$ Films were cast by slow evaporation of polymer solutions in DMAc. F: Flexible; B: Brittle, cracked upon creasing. ${ }^{\mathrm{e}}$ Insoluble in available organic solvents.

an increased intermolecular interaction. In addition, it is interesting to note that polymer $p-\mathbf{4 f}$ displayed a semicrystalline pattern, whereas its corresponding analogue $(m-\mathbf{4 f})$ displayed a nearly completely amorphous pattern. The WAXD pattern of $p-\mathbf{4 f}$ indicates that the incorporation of flexible ether linkages does not necessarily reduce the polymer crystallinity dramatically because it may increase the probability of the formation of hydrogen bonding. However, in the case of $m-\mathbf{4 f}$, the incorporation of both ether and $m$-phenylene groups into the polymer chain may disrupt interchain hydrogen bonding, thus preventing the close packing of chains. The polymers that could afford flexible and tough films as listed in Table I showed amorphous patterns.

The solubility of the poly(ester amide)s was determined qualitatively (Table II). In general, the semicrystalline polymers revealed a poor solubility. For example, $p$-4a and $p-\mathbf{4 d - f}$ were insoluble in any of the solvents tested. In contrast, the amorphous poly(ester amide)s exhibited a higher solubility; they were soluble in most polar aprotic solvents. The polymers derived from multiring flexible diacids, such as $m-\mathbf{4 i}$ and $m-\mathbf{4 j}$, also showed solubility in less efficient $m$-cresol and THF. In general, the solubility behavior of the $p-\mathbf{4}$ series poly(ester amide)s is comparable to that of the corresponding poly(ether amide)s obtained from 2,7bis(4-aminophenoxy)naphthalene. ${ }^{18}$ As mentioned earlier, most of the amorphous poly(ester amide)s could be solution-cast into flexible and tough films. Some of these films were subjected to tensile test, and their tensile properties are summarized in Table III. Tensile strengths of 63-90 MPa and initial moduli of 1.7-2.0 GPa qualify them as strong and rigid materials.

The thermal properties of the poly(ester amide)s evaluated by DSC, TMA, and TGA are summarized in Table IV. $T_{\mathrm{g}}$ of these polyamides was obtained from the middlepoint temperature of baseline shift on the second DSC heating trace (heating rate $=20^{\circ} \mathrm{C} \mathrm{min}^{-1}$ ) after rapid cooling from $400{ }^{\circ} \mathrm{C}$ (cooling rate $=200^{\circ} \mathrm{C}$ $\mathrm{min}^{-1}$ ). Three of semicrystalline poly(ester amide)s such as $p-\mathbf{4 a}, p-\mathbf{4 e}$, and $p-\mathbf{4 f}$ showed no discernible $T_{\mathrm{g}} \mathrm{s}$ on their DSC curves. The other poly(ester amide)s showed clear $T_{\mathrm{g}}$ between $187^{\circ} \mathrm{C}$ and $237^{\circ} \mathrm{C}$ by DSC, generally following the increasing order of chain rigidity, steric hindrance, and polarity of the diacid and diamine residues. The $p-\mathbf{4}$ series poly(ester amide)s showed a higher $T_{\mathrm{g}}$ as compared to the corresponding $m-\mathbf{4}$ series counterparts because of the difference in symmetry between para and meta catenations. The lowest $T_{\mathrm{g}}$ of $187^{\circ} \mathrm{C}$ was observed for poly(ester amide)s 


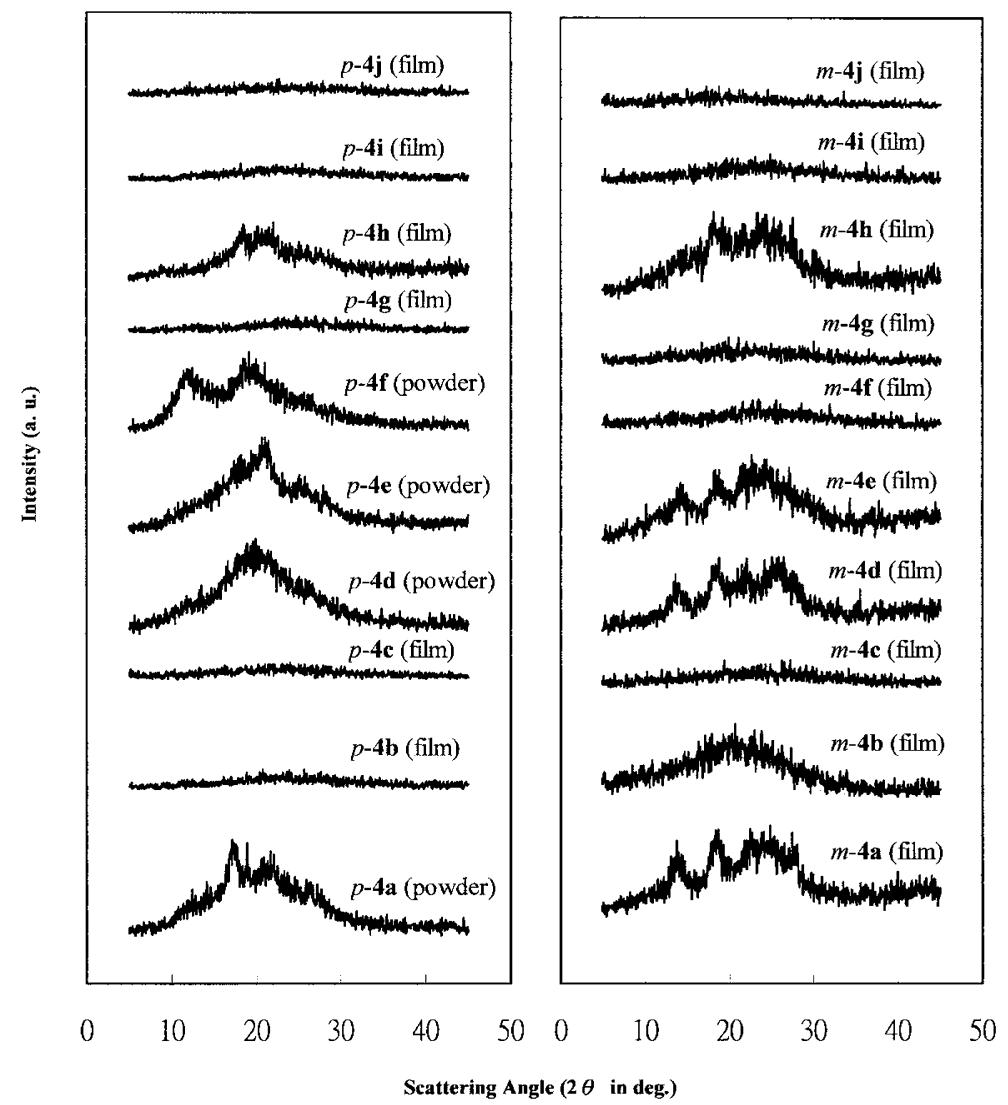

Figure 4. Wide-angle X-Ray diffractograms of poly(ester amide)s $p-\mathbf{4 a - j}$ and $m-\mathbf{4 a - j}$.

Table II. The solubility behavior of poly(ester amide)s

\begin{tabular}{|c|c|c|c|c|c|c|}
\hline \multirow{2}{*}{ Polymer code } & \multicolumn{6}{|c|}{ Solubility $^{\mathrm{a}}$} \\
\hline & NMP & DMAc & DMF & DMSO & $m$-Cresol & THF \\
\hline$p-\mathbf{4 a}$ & - & - & - & - & - & - \\
\hline$p-\mathbf{4 b}$ & + & + & - & - & - & - \\
\hline$p-4 c$ & + & + & + & + & $+\mathrm{h}$ & - \\
\hline$p-4 d$ & - & - & - & - & - & - \\
\hline$p-4 \mathrm{e}$ & - & - & - & - & - & - \\
\hline$p-\mathbf{4 f}$ & - & - & - & - & - & - \\
\hline$p-\mathbf{4 g}$ & + & + & + & + & $+\mathrm{h}$ & + \\
\hline$p-4 h$ & + & + & - & $+\mathrm{h}$ & - & - \\
\hline$p-4 \mathbf{i}$ & + & + & + & + & $+\mathrm{h}$ & - \\
\hline$p-\mathbf{4} \mathbf{j}$ & + & + & + & + & + & - \\
\hline$m-\mathbf{4 a}$ & + & + & - & - & - & - \\
\hline$m-4 b$ & + & + & + & + & $+\mathrm{h}$ & - \\
\hline$m-4 c$ & + & + & + & + & + & + \\
\hline$m-\mathbf{4 d}$ & + & + & - & - & - & - \\
\hline$m-4 \mathrm{e}$ & $+\mathrm{h}$ & - & - & - & - & - \\
\hline$m-\mathbf{4 f}$ & + & + & + & + & - & - \\
\hline$m-\mathbf{4 g}$ & + & + & + & + & + & + \\
\hline$m-4 h$ & + & + & - & $+\mathrm{h}$ & - & - \\
\hline$m-\mathbf{4 i}$ & + & + & + & + & + & + \\
\hline$m-\mathbf{4} \mathbf{j}$ & + & + & + & + & + & + \\
\hline
\end{tabular}

${ }^{a}$ Qualitative solubility tested with $10 \mathrm{mg}$ of sample in $1 \mathrm{~mL}$ of the solvent. +: soluble at room temperature; + h: soluble on heating at $100{ }^{\circ} \mathrm{C}$; - : insoluble even on heating. NMP: $N$-methyl-2-pyrrolidone; DMAc: $N, N$ dimethylacetamide; DMF: $N, N$-dimethylformamide; DMSO: dimethyl sulfoxide; THF: tetrahydrofuran.

$m-\mathbf{4 b}$ and $m-\mathbf{4 f}$ derived from diamino-diester $m-\mathbf{2}$ with flexible isophthalic acid (3b) and 4,4'-oxydibenzoic acid (3f). The high $T_{\mathrm{g}}$ value $\left(237^{\circ} \mathrm{C}\right)$ of poly(ester amide) $p-4 \mathrm{~h}$ are believed to be due to the presence of 
Table III. Mechanical properties of some poly(ester amide) films

\begin{tabular}{cccc}
\hline Polymer code & $\begin{array}{c}\text { Tensile strength } \\
(\mathrm{MPa})\end{array}$ & $\begin{array}{c}\text { Elongation to break } \\
(\%)\end{array}$ & $\begin{array}{c}\text { Initial modulus } \\
(\mathrm{GPa})\end{array}$ \\
\hline$p-\mathbf{4 b}$ & 87 & 12 & 2.0 \\
$p-\mathbf{4 c}$ & 85 & 14 & 2.0 \\
$p-\mathbf{4 g}$ & 82 & 15 & 1.7 \\
$p-\mathbf{4 i}$ & 82 & 11 & 1.8 \\
$p-\mathbf{4 j}$ & 81 & 10 & 1.7 \\
$m-\mathbf{4 c}$ & 84 & 7 & 2.0 \\
$m-\mathbf{4 f}$ & 89 & 8 & 2.0 \\
$m-\mathbf{4 g}$ & 90 & 10 & 1.8 \\
$m-\mathbf{4 i}$ & 63 & 6 & 1.9 \\
$m-\mathbf{4 j}$ & 79 & 9 & 1.7 \\
\hline
\end{tabular}

Table IV. Thermal properties of poly(ester amide)s

\begin{tabular}{|c|c|c|c|c|c|}
\hline \multirow{2}{*}{ Polymer code } & \multirow{2}{*}{$T_{\mathrm{g}}\left({ }^{\circ} \mathrm{C}\right)^{\mathrm{a}}$} & \multirow{2}{*}{$\begin{array}{l}T_{\mathrm{s}}^{\mathrm{b}} \\
\left({ }^{\circ} \mathrm{C}\right)\end{array}$} & \multicolumn{2}{|c|}{$T_{\mathrm{d}}^{\mathrm{c}}\left({ }^{\circ} \mathrm{C}\right)$} & \multirow{2}{*}{$\begin{array}{c}\text { Char yield }^{\mathrm{d}} \\
(\%)\end{array}$} \\
\hline & & & In $N_{2}$ & In Air & \\
\hline$p-\mathbf{4 a}$ & $--^{\mathrm{e}}(426)^{\mathrm{f}}$ & $-\mathrm{g}$ & 414 & 401 & 61 \\
\hline$p-4 b$ & $212(365)^{\mathrm{f}}$ & 207 & 426 & 428 & 62 \\
\hline$p-4 c$ & 226 & 224 & 437 & 430 & 54 \\
\hline$p-4 d$ & 216 & - & 445 & 447 & 59 \\
\hline$p-4 \mathrm{e}$ & $-(433)^{\mathrm{f}}$ & - & 470 & 456 & 55 \\
\hline$p-\mathbf{4 f}$ & $-(369)^{\mathrm{f}}$ & - & 465 & 443 & 55 \\
\hline$p-4 g$ & 228 & 235 & 457 & 451 & 55 \\
\hline$p-4 h$ & $237(372)^{\mathrm{f}}$ & - & 431 & 430 & 59 \\
\hline$p-4 \mathbf{i}$ & 204 & 208 & 453 & 446 & 53 \\
\hline$p-4 \mathbf{j}$ & 191 & 196 & 448 & 449 & 53 \\
\hline$m-\mathbf{4 a}$ & $193(361)^{\mathrm{f}}$ & - & 409 & 409 & 61 \\
\hline$m-\mathbf{4 b}$ & 187 & - & 403 & 406 & 61 \\
\hline$m-4 c$ & 198 & 200 & 437 & 432 & 59 \\
\hline$m-\mathbf{4 d}$ & $210(368)^{f}$ & - & 434 & 437 & 64 \\
\hline$m-4 \mathbf{e}$ & $206(367)^{\mathrm{f}}$ & - & 428 & 424 & 56 \\
\hline$m-\mathbf{4 f}$ & 187 & 186 & 447 & 439 & 63 \\
\hline$m-4 g$ & 209 & 215 & 470 & 460 & 58 \\
\hline$m-4 \mathrm{~h}$ & $215(352)^{\mathrm{f}}$ & - & 449 & 441 & 61 \\
\hline$m-4 \mathbf{i}$ & 192 & 195 & 467 & 454 & 59 \\
\hline$m-\mathbf{4 j}$ & 188 & 186 & 465 & 449 & 59 \\
\hline
\end{tabular}

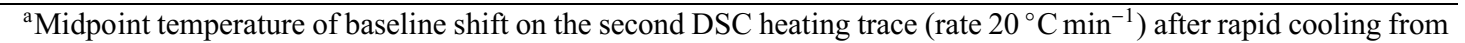
$400{ }^{\circ} \mathrm{C}$ at $-200{ }^{\circ} \mathrm{C} \mathrm{min}^{-1}$. b Softening temperature measured by TMA (penetration method) with a constant applied load of $10 \mathrm{mN}$ at a heating rate of $10{ }^{\circ} \mathrm{C} \mathrm{min}^{-1}$. ${ }^{\mathrm{c}}$ Decomposition temperature at which a $10 \%$ weight loss was recorded by TGA at a heating rate of $20^{\circ} \mathrm{C} \mathrm{min}^{-1}$. ${ }^{\mathrm{d}}$ Residual weight $\%$ at $800{ }^{\circ} \mathrm{C}$. ${ }^{\mathrm{e}}$ No discernible transition was observed. ${ }^{\mathrm{f}} \mathrm{Peak}$ top temperature of the medium-intensity melting endotherm on the first DSC heating trace. ${ }^{\mathrm{g}}$ Not detected.

polar sulfonyl groups that causes an increased intermolecular interaction. All the poly(ester amide)s that revealed a semicrystalline WAXD pattern showed clear medium-intensity melting endotherms with peak top temperatures at around 352 to $433{ }^{\circ} \mathrm{C}$ on the first DSC heating traces. Typical DSC thermograms of polymer $m-\mathbf{4 a}$ are illustrated in Figure 5. Probably due to the presence of flexible ester linkages, the $p$-series poly(ester amide)s generally exhibited lower $T_{\mathrm{g}}$ values and melting temperatures in comparison with the corresponding poly(ether amide)s reported in literature. ${ }^{18}$ The softening temperatures $\left(T_{\mathrm{s}}\right)$ (may be referred as apparent $T_{\mathrm{g}}$ ) of the poly(ester amide) films were determined by the TMA method using a loaded penetration probe. They were read from the onset temperature of the probe displacement on the TMA trace. As can be seen from Table IV, the $T_{\mathrm{s}}$ values of some poly(ester amide) films were recorded in the range of $196-235^{\circ} \mathrm{C}$ for the $p$-series and $186-215^{\circ} \mathrm{C}$ for the $m$-series. In most cases, the $T_{\mathrm{s}}$ values obtained by TMA are comparable to the $T_{\mathrm{g}}$ values measured by the DSC experiments. The trend of $T_{\mathrm{s}}$ variation with the chain stiffness is similar to that of $T_{\mathrm{g}}$ observed in the DSC measurements.

Thermal and thermo-oxidative stabilities of these poly(ester amide)s were evaluated under both nitrogen and air atmospheres using a $10 \mathrm{wt} \%$ loss values $\left(T_{\mathrm{d}}\right)$ for comparison by TGA. All the poly(ester amide)s ex- 


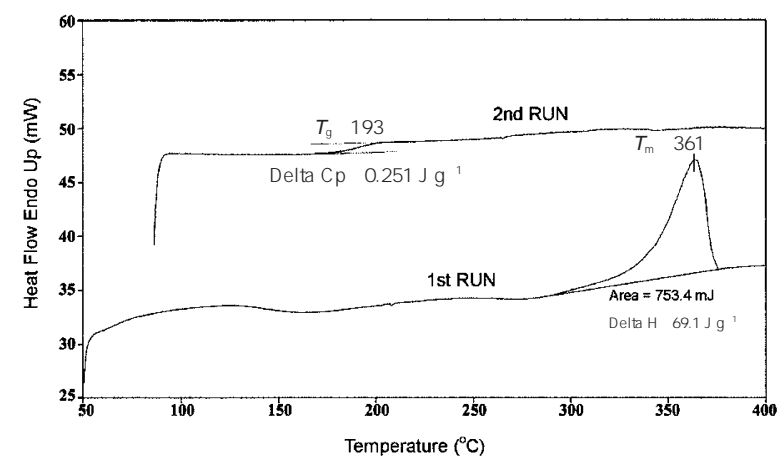

Figure 5. DSC thermograms of poly(ester amide) $m-\mathbf{4 a}$.

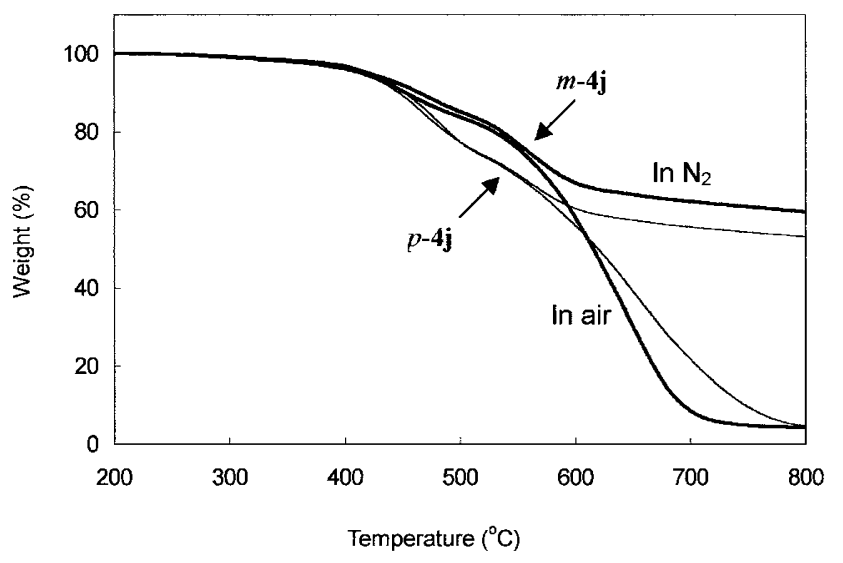

Figure 6. TGA curves of poly(ester amide)s $p-\mathbf{4 j}$ and $m-\mathbf{4 j}$ (Heating rate $=20^{\circ} \mathrm{C} \mathrm{min}^{-1}$ ).

hibited good thermal stability with insignificant weight loss up to temperatures of approximately $400^{\circ} \mathrm{C}$ in both air and nitrogen atmospheres, and the anaerobic char yields at $800{ }^{\circ} \mathrm{C}$ for all polymers were in the range of 53-64 wt $\%$. The $T_{\mathrm{d}}$ values for the $p$-series poly(ester amide)s ranged from 414 to $470{ }^{\circ} \mathrm{C}$ in nitrogen and 401 to $456{ }^{\circ} \mathrm{C}$ in air, which were lower than those of the analogous poly(ether amide)s because of the less stable ester groups. The $T_{\mathrm{d}}$ values for the $m$-series poly(ester amide)s stayed in the range of 403 to $470{ }^{\circ} \mathrm{C}$ in nitrogen and 406 to $460{ }^{\circ} \mathrm{C}$ in air. Typical TGA curves of poly(ester amide)s $p-\mathbf{4 j}$ and $m-\mathbf{4} \mathbf{j}$ were reproduced in Figure 6. All poly(ester amide)s seemed to exhibit a two-stage decomposition behavior at elevated temperatures. The first stage of weight loss starting around $400{ }^{\circ} \mathrm{C}$ might be attributed to the early degradation of the less stable ester groups. IR spectra of the solid residues of the polymers after heat treatment were examined. Figure 7 shows IR spectra of a thin film of $p$ 4b after being heated sequentially in air each for $30 \mathrm{~min}$ at $300,350,400$, and $425^{\circ} \mathrm{C}$. The IR spectra of $p-4 \mathbf{b}$ after heat treatment at $300^{\circ} \mathrm{C}$ and $350{ }^{\circ} \mathrm{C}$ remained almost the same as before heat treatment. After heating at $400{ }^{\circ} \mathrm{C}$ for $30 \mathrm{~min}$, a decrease in relative intensities around 1732,1269 , and $1140 \mathrm{~cm}^{-1}$ indicates some loss of ester functionalties. After further heating at $425^{\circ} \mathrm{C}$,

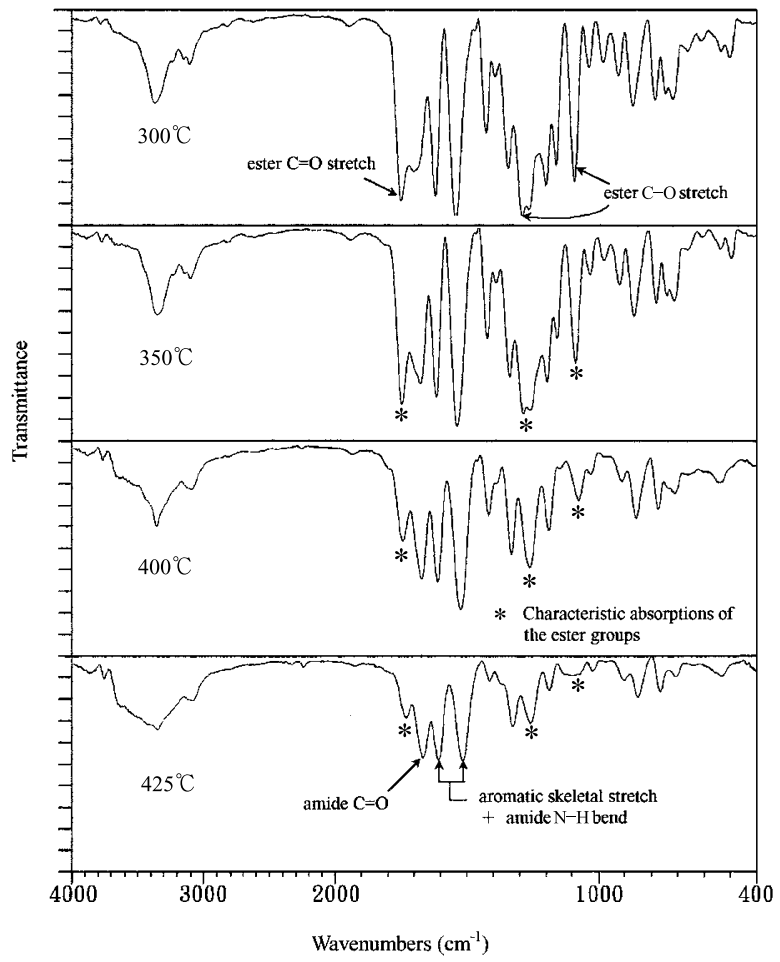

Figure 7. FT-IR spectra (thin films) of $p-\mathbf{4 b}$ after sequential heating in air at the indicated temperatures, each for $30 \mathrm{~min}$.

an obvious decrease in intensities of the ester absorption bands was observed, while a high content of amide functionalties and aromatic skeletons was still detected.

Preliminary investigation on the thermal decomposition mechanisms of these poly(ester amide)s was carried out by using pyrolysis-GC/MS. Typical pyrograms of a representative poly(ester amide) $p$-4a instantly heated at $300,350,400$, and $450{ }^{\circ} \mathrm{C}$ are illustrated in Figure 8. Structures assignments of the relevant pyrolysis compounds were based on their major mass fragments. Table $\mathrm{V}$ lists five identified pyrolysis products of $p-\mathbf{4 a}$ in pyrolysis-GC/MS at $450{ }^{\circ} \mathrm{C}$ in helium. As can be seen from Figure 8, the most abundant pyrolysis compound evolved at $300-450{ }^{\circ} \mathrm{C}$ is due to 2,7-dihydroxynaphthalene $(\mathrm{m} / \mathrm{z} 160)$. The evolution of 2,7-dihydroxynaphthalene from the decomposition of the ester groups starts at around $300^{\circ} \mathrm{C}$ and reaches a greater intensity at around $400{ }^{\circ} \mathrm{C}$. The other thermal degradation compounds evolved at $450^{\circ} \mathrm{C}$ are mainly due to $N$-phenylbenzamide (m/z 197), 4aminobenzonitrile (m/z 118), 2-naphthol (m/z 144), and benzoic acid $(\mathrm{m} / \mathrm{z} 122)$. It can be noticed that $2,7-$ dihydroxynaphthalene was evolved exclusively within the pyrograms at 300 and $350{ }^{\circ} \mathrm{C}$, indicating that the ester bonds are apparently the weakest units of poly(ester amide) $p$-4a. This result is in good agreement with the changes in IR spectra when heating these poly(ester amide)s at elevated temperatures. Further studies that may allow a detailed schematization of the thermal 
Table V. Identification of the pyrolysis products in pyrolysis-GC/MS of $p-\mathbf{4 a}$ at $450{ }^{\circ} \mathrm{C}$ in helium

\begin{tabular}{|c|c|c|c|c|}
\hline $\begin{array}{l}\text { Retention } \\
\text { time (min) }\end{array}$ & Compound & Structural formula & Major mass fragments & $\begin{array}{c}\text { Quality } \\
\text { (Library searched) }\end{array}$ \\
\hline 7.31 & Benzoic acid & & $51,77,105,122$ & 95 \\
\hline 9.24 & 4-Aminobenzonitrile & & $64,91,118$ & 91 \\
\hline 9.72 & 2-Naphthol & & 115,144 & 93 \\
\hline 11.63 & 2,7-Dihydroxynaphthalene & & $77,103,131,160$ & 91 \\
\hline 12.23 & $N$-Phenylbenzamide & 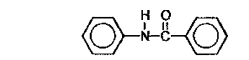 & $51,77,105,197$ & 90 \\
\hline
\end{tabular}

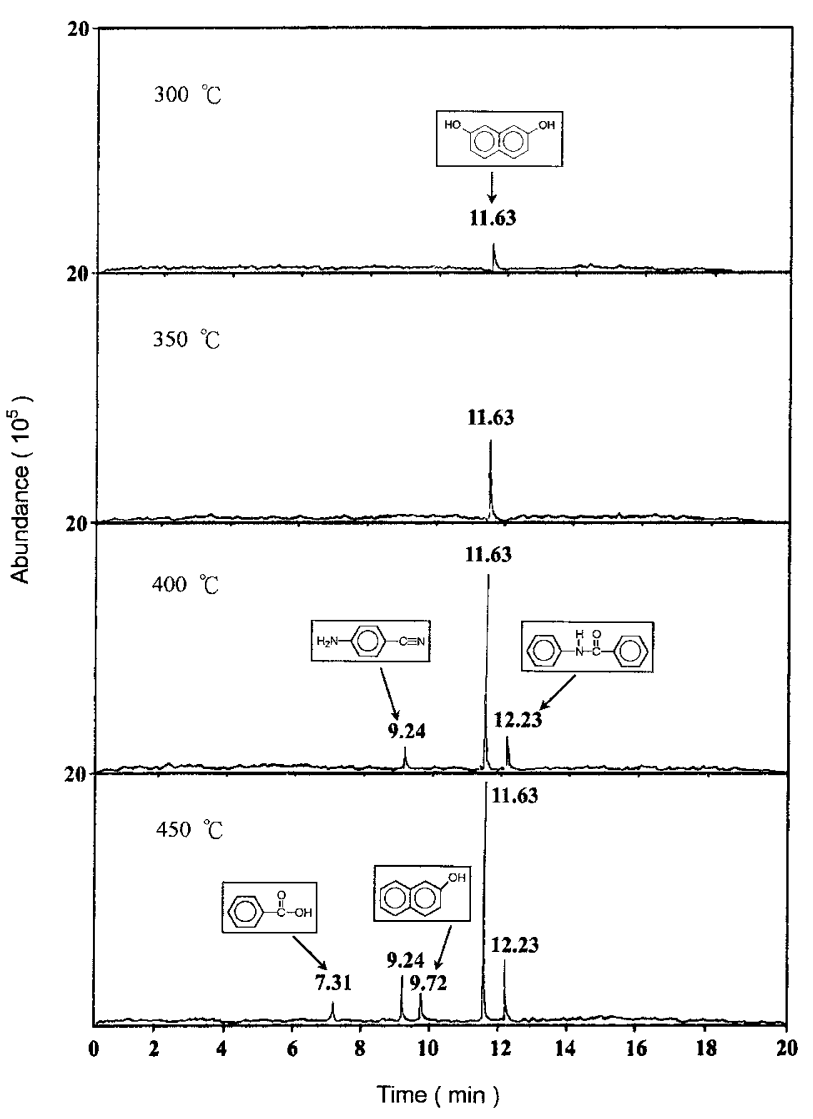

Figure 8. Pyrograms obtained in the pyrolysis-GC/MS of polymer $p$-4a at $300,350,400$, and $450^{\circ} \mathrm{C}$ in helium.

degradation pathways involved in the degradation of these poly(ester amide)s are in progress.

\section{CONCLUSIONS}

Two novel bis(benzoyloxy)naphthalene-containing aromatic diamines, $p-\mathbf{2}$ and $m-\mathbf{2}$, have been successfully synthesized in high purity and high yields from the condensation reaction of 2,7-dihydroxynaphthalene with 4-nitrobenzoyl chloride and 3-nitrobenzoyl chloride and subsequent hydrogen catalytic reduction of the intermediate dinitro compounds. Two series of aromatic poly(ester amide)s with moderate to high inherent viscosities were prepared from $p$-2 and $m$ -
2 with various aromatic dicarboxylic acids by means of triphenyl phosphite and pyridine. The poly(ester amide)s obtained from rigid dicarboxylic acids such as terephthalic acid (3a), 4,4'-biphenyldicarboxylic acid (3d), 2,6-naphthalenedicarboxylic acid (3e) and 4,4'sulfonyldibenzoic acid (3h) were generally semicrystalline and showed less solubility. Most of the amorphous poly(ester amide)s displayed good solubility, good film-forming capability, reasonable thermal stability, and moderate $T_{\mathrm{g}}$ or $T_{\mathrm{s}}$ values suitable for thermoforming processing. Investigation of the thermal degradation of the poly(ester amide)s using IR spectroscopy and pyrolysis-GC/MS indicated that ester groups are the thermal weak points of these polymers.

Acknowledgments. The authors thank the National Science Council of Taiwan for financial support.

\section{REFERENCES}

1. P. W. Morgan, Chemtech., 9, 316 (1979).

2. H. H. Yang, "Aromatic High-Strength Fibers", John Wiley \& Sons, Inc., New York, N.Y., 1989, p 66.

3. H. H. Yang, "Kevlar Aramid Fiber", John Wiley \& Sons, Ltd., Chichester, 1993, p 25.

4. G. Maglio, R. Palumbo, and M. C. Vignola, Macromol. Chem. Phys., 196, 2775 (1995).

5. S.-H. Hsiao and C.-H. Yu, J. Polym. Res., 3, 247 (1996).

6. S.-H. Hsiao and P.-C. Huang, Macromol. Chem. Phys., 198, 4001 (1997).

7. F. Akutsu, M. Inoki, M. Sawano, Y. Kasashima, K. Naruchi, and M. Miura, Polymer, 39, 6093 (1998).

8. G. C. Eastmond, J. Paprotny, and R. S. Irwin, Polymer, 40, 469 (1999).

9. S.-H. Hsiao, C.-P. Yang, and S.-H. Chen, Polymer, 41, 6537 (2000).

10. Y. Imai, N. N. Maldar, and M. Kakimoto, J. Polym. Sci., Part A: Polym. Chem., 23, 1797 (1985).

11. H. J. Jeong, Y. Imai, and M. Kakimoto, J. Polym. Sci., Part A: Polym. Chem., 29, 767 (1991).

12. C.-P. Yang and J.-H. Lin, J. Polym. Sci., Part A: Polym. Chem., 31, 2153 (1993). 
13. J. F. Espeso, J. G. de la Campa, A. E. Lozano, and J. de Abajo, J. Polym. Sci., Part A: Polym. Chem., 38, 1014 (2001).

14. G.-S. Liou, M. Maruyama, M. Kakimoto, and Y. Imai, J. Polym. Sci., Part A: Polym. Chem., 31, 2499 (1993).

15. G.-S. Liou, M. Maruyama, M. Kakimoto, and Y. Imai, J. Polym. Sci., Part A: Polym. Chem., 36, 2029 (1998).

16. Y. Imai, High Perform. Polym., 7, 337 (1995).

17. Y. Imai, React. Funct. Polym., 30, 3 (1996).

18. C.-P. Yang and W.-T. Chen, Makromol. Chem., 193, 2323 (1992).
19. C.-P. Yang, S.-H. Hsiao, and C.-C. Jang, J. Polym. Sci., Part A: Polym. Chem., 33, 1095 (1995).

20. C.-P. Yang, S.-H. Hsiao, and C.-C. Jang, J. Polym. Sci., Part A: Polym. Chem., 35, 2147 (1997).

21. S.-H. Hsiao and K.-Y. Chu, Macromol. Chem. Phys., 198, 819 (1997).

22. S.-H. Hsiao and G.-S. Liou, Macromol. Chem. Phys., 199, 2321 (1998).

23. N. Yamazaki, M. Matsumoto, and F. Higashi, J. Polym. Sci., Polym. Chem. Ed., 13, 1373 (1975). 